\title{
Teaching English Technical Writing to Japanese Specialists
}

\section{Yoshiaki Shinoda}

\begin{abstract}
Instructors of technical writing can teach Japanese specialists, more effectively by being aware of some basic linguistic differences between Japanese and native English-speaking technical writers. One of the difficulties with traditional instruction is that it is prepared from the native speaker's point of view. Instruction should be prepared to meet the foreign students' needs. Japanese students experience difficulty in three areas: First, they have trouble with technical terms, often relying too literally on a dictionary to offer a synonym. The consequence is their selecting imprecise terms which in turn produce an awkward expression. Second, Japanese students have trouble with English grammar-in particular with articles, prepositions, tenses, auxiliary verbs, and the subjunctive mood. Finally, they are challenged by rhetoric, that is, choosing and arranging words effectively. Examples of each problem are offered with suggestions on how to make the students more aware of the principles involved.
\end{abstract}

Perhaps at no time in history has English been as important to people all over the world as it is today. With countries being swept into the turmoil of international affairs, businessmen and diplomats have discovered that the best way to keep afloat is to have a good command of English.

In 1978, while attending classes on technical writing at the Uni○本論交は早稻田商学研究基金の萪助による。

OReprinted from IEEE Transactions on Professional Communication, Sept. 1982. 
versity of Michigan, I devised a number of methodologies for teaching English for Science and Technology (EST) technical writing to Japanese specialists. Here are some of my ideas. Many may be valid for specialists of other nationalities.

\section{THE IMPORTANCE OF UNDERSTANDING THE REAL SITUATION}

Some professors in American colleges and universities seem to have problems improving the English of non-native students. The traditional approach to solving these problems has been to develop the student's understanding of sentence structure and the basic skills of reading and writing. The teachers, being native English speakers themselves, tend to instruct their foreign students from the native speakers' point of view. Many may consider the non-native students to be-for all practical purposes-the same as their native-speaker students. Hence, the methodologies they use are no different from those they use for American students. The teacher should be aware of how those foreign students were taught English in their native countries and what the weak points of their English background are so that they can develop methodologies appropriate to the students' needs.

American professors often say that foreign students cannot follow lectures on material covered in the course text. The reason for this is that their ability to understand spoken English-their aural comprehension capability-is rather poor. Thus, American teachers mistakenly believe that the Japanese students' English is poor in all areas. Yet syntax is one area in which the Japanese excel. The amount of grammatical information that Japanese students must master to pass a university entrance examination in Japan is mind-boggling to a native speaker of English. There is no need for American professors to teach Japanese specialists such grammatical points as countable and uncountable nouns, subject-verb agreement, and the use of 
relative pronouns.

Generally speaking, Japanese students are strong in reading comprehension but weak in writing and even weaker in understanding spoken English and speaking it themselves. The reason is not difficult to comprehend. In Japan, lectures on English are given in Japanese and there are few opportunities to converse in English. Students must only be able to read, comprehend, and translate written English. In the following pages I show some of the problems Japanese students and specialists face and my approach to their solutions.

\section{THREE IMPORTANT FACTORS}

A systematic teaching method must be followed. Three components should be kept fimly in mind: technical and semi-technical terms, English grammar, and rhetoric.

\section{Technical and Semi-technical Terms}

Most English technical terms are internationally understood; they are common throughout the world. A technical term is a kind of "tag," which is firmly set. Therefore, if someone uses such a term in another setting, the reader misunderstands. In effect, the writer fails to convey the idea. A technical term also should not be paraphrased because the intended meaning sometimes is lost. If the exact technical term does not pop into our head, we should look for it in a technicalterm dictionary. Although there is no clear distinction between technical and semi-technical terms, technical terms are neither ambiguous nor obscure (for example, cathode ray, direct current, ignition, and steering wheel). Semi-technical terms, on the other hand, have similar denotations. For example, a general word-_"river"-can convey more than one meaning or quality. The river can denote a stream, a brook, a streamlet, a riverlet, a waterway, a creek, a runlet, or a watercourse. Thus, "river" belongs to the semi-technical term group, while words with a clearly singular denotation belong to the technical group. 
Correct word choice varies according to the writing task and is essential to effective writing.

When Japanese writers wish to denote a "vehicle," they almost always select the word "automobile" or "car." But trucks are also vehicles. Let's say they want "passenger vehicle." The word "automobile" or "car" can be overly vague. The reader might ask, "What kind of automobile do you mean?" The writer might answer, "A passenger car." "Passenger car" is still not clear. The reader might then ask, "What kind of passenger car?" The writer might reply, "A Ford." Then, "What kind of Ford?" The writer may answer, "A Mercury station wagon." Such questions might continue until the reader grasps the core word, in this case,-say, "1981 Mercury station wagon."

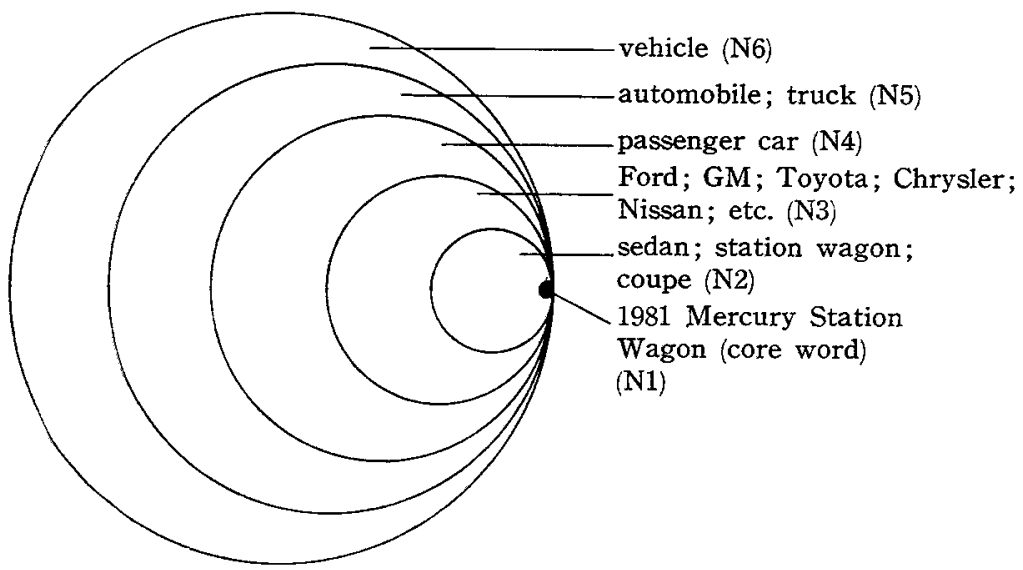

Figure: Relations among technical terms.

Writers should try to find the core word when writing a technical paper. The reason is that specific word helps the reader to grasp the meaning precisely and quickly.

Here are some examples of what Japanese writers often produce:

- Our clock can be operated on a battery. 
- The rear seat will hold three people.

In the first sentence, "battery" can be more precisely written: "size AA battery." In the second sentence, "people" is ambiguous and could be replaced by a more precise word like "children."

It is unnecessary for teachers of English to teach technical definitions to the student because such terms are usually taught in the various technical courses. These terms can be left to the science or engineering professors or to the student to learn on his own through a technical-term dictionary. Also, on-the-job training in a particular field enhances the likelihood of mastering the real meaning of those terms. Though we do not need to teach the meaning of the technical terms, we should teach the student how to use them.

One of the most difficult problems that confront foreign students is noun-verb matching. This problems appears in almost all composition written by Japanese. The reason, of course, is that they have the expression of their mother tongue in their minds.

Let me give you a few examples:

- In order to stop the bell, push the button.

- To avoid the rain, cover the motor.

- Beware of our brand. (instead of "Buy only our brand.")

- To write a map, . . .

There are also many strange adjective-noun matchings. For example:

- A flexible computer (instead of a versatile computer)

- tender light (instead of soft light)

- a clear water (instead of drinking water)

- a big speed (instead of a high speed)

One reason why such mismatches occur is that students use a Japanese-English dictionary to find only a single word. The important thing is to find the exact, correct technical or semi-technical termusually a noun-and then find the proper verb to match it, and then find an adjective if one is necessary. The rule is: first select the noun and then the verb. Otherwise the students' sentences will be Japanese- 
English rather than English.

It is quite natural that a core word such as a very precise technical term (e.g., 1981 Mercury station wagon) cannot be found in a common dictionary or even in a technical-term dictionary. Or even if found, a matching verb or adjective is not shown. But we need not give up. The core word "1981 Mercury station wagon" is not likely to be found in any dictionary. Therefore, we should try to find N5 or $\mathrm{N} 6$ (see the diagram) in a dictionary (We can go from exceedingly technical terms to the more common term). Most dictionaries contain common words with matching verbs and adjectives. Any verb that matches N5 or N6 will also match any lower numbered N.

When we develop sentences into paragraphs, we must use pronouns. In English technical writing, I suggest avoiding the pronouns "it" and "they" when possible in favor of using the "noun pronoun," that is, N2, N3, N4, N5, or N6. For example:

While chess experts deplore a scientist's suggestion that a computer will [someday] be world champion..., the electronic brain gives even more convincing demonstrations of its ability in this direction.-D. S. Halacy, Nine Roads to Tomorrow [1].

The wet-plate coating techniques required practiced timing, nimble fingers, and an experienced wrist motion. In a darkroom, under a yellowish light, the plate was balanced horizontally on the fingertips of one hand; the thick, gluelike collodion was poured onto the center of the plate with the other hand. -E. Ostroff, Photography [2].

$\mathrm{N} 2, \mathrm{~N} 3, \mathrm{~N} 4, \mathrm{~N} 5$, or $\mathrm{N} 6$ can thus be used as the anaphoric noun for effective technical writing. To produce clear and effective technical writing, we should look for the core word; the core noun and verb.

Certain English words often mislead Japanese students or business people. Most such words are synonyms like the following groupings:

- complete, perfect

- warning, caution, note, important 
- break, breakdown, failure, out of order, out of service, trouble

- approach, method, procedure, process, technique, way

- defective, faulty

All of the words in each group are translated into Japanese by a single term-exactly the same term. The root cause of the difficulty is that students are using English-Japanese and Japanese-English dictionaries.

\section{English Grammar}

Almost all Japanese specialists can recognize subordinate clauses, adverbs, gerunds, and infinitives. These specialists do have difficulty, however, in five areas: (1) articles, (2) tenses, (3) auxiliary verbs, (4) prepositions, and (5) subjunctive mood. Almost all Japanese students know that an indefinite article should be placed before a countable singular noun and that a definite article goes before a specific noun. They experience difficulty though, in using indefinite articles with uncountable nouns: "at $a$ high speed," "a knowledge of computers." They cannot distinguish between "fish live in the water" and "sugar dissolves in water" (no article), " $a$ demand for oil" and "the demand for oil."

Where an American would write "install the outlet in the wall," the Japanese would say "install the outlet on the wall." The Japanese thinks of the car driver "sitting in front of the wheel" and is confused by the American saying "behind the wheel." Teachers should explain the reasons for such usage-not require the students simply to learn them by heart. The student must learn the precise reason why "a" is used here or why "behind" is used there, and so on. I have written about these five areas of difficulty in "Pitfalls for Japanese Specialists in Technical Writing," Journal of Technical Writing and Communication [3].

Perhaps some examples will help clarify what I have been saying. Take the rule: When composing a sentence, first choose the correct noun, then the verb, and then write the sentence. Suppose we are 
translating a Japanese sentence into English and we have chosen the following nouns:

boiler/factory/space

Let's make a sentence using these:

The boiler which is installed in our factory does not occupy narrow space.

This is translated literally from the Japanese original. Lots of Japanese students write like this. I advise them first to check noun-verb matching: "boiler," "install," "factory," "occupy," and "space." Then they are to look at the adjective-noun matching-"narrow space." If students feel uncertain about the word "narrow," they are encouraged to check it in English-English dictionary. For example, The American Heritage Dictionary of the English Language says:

narrow-Of small or limited width, especially in comparison with length.

Students might feel that "narrow" is inappropriate. If so, they should check "space" in the dictionary for examples of suitable adjectives. Students then replace "narrow" with "limited." Next, they should check grammatical errors, and cut unnecessary words-"which is" can be deleted; sometimes "installed" can be cut. (In this case, deleting "installed" might render the sentence ambiguous because one would not know whether the boiler is installed or not.) The result is the better sentence:

The boiler installed in our factory takes limited space.

If we change the subject from "The boiler" to "The air conditioner," I advise students to put a word "floor," "ceiling," or "wall" between "limited" and "space" to make the sentence clearer even if these adjectives are not involved in the original Japanese version. For example:

The air conditioner installed in our factory requires only limited floor (or ceiling or wall) space. 
Here is another example translated from a Japanese original:

If the power should be off, the magnetism of the coil will disappear.

In this sentence, I advise the student to check the noun "magnetism" and the verb "disappear." The American Heritage Dictionary of the English Language explains:

disappear-1. To pass out of sight either suddenly or gradually; vanish. 2. To die out; become extinct.

The students might decide from these definitions that "disappear" does not match with "magnetism." Or if a student has written:

When the power is off, ...

I explain that he seems to be expecting the condition and thus should write:

If the power should be off, . .

Further if they feel uneasy about the "of" in front of "coil," then a "noun + noun" construction could be used. Thus,

If the power should be off, the coil magnetism will be lost.

To more experienced students, I explain that the following sentence is better:

If the power should be off, the magnetism will be lost in the coil.

When an English sentence ends with the predicative verb and there is a prepositional modifier in the subject, it is better to place the modifier at the end of the sentence for balance. All three English sentences, when translated into Japanese, result in the same sentence.

\section{Rhetoric}

Rhetoric is a new and challenging field for almost all Japanese specialists and students; hardly any Japanese college or university teaches it. Rhetoric deals with the choice of words (diction) and with 
the effective arrangement of words and sentences (style). Therefore, EST does not seem to exist without rhetoric. In my lectures I explain unity, coherence, cause and effect, definition, and order.

For example, starting from a Japanese sentence, the students might have written:

The parts which are rotating with high speed must be well lubricated.

I suggest that the students check the dictionary. "With" is strange; we can also eliminate "which are." This part can be rewritten:

The parts rotating with (at) high speed ...

If students feel uncertain about "with" or "at," "a high speed" or "high speed" or "high speeds," they can substitute "high-speed rotating parts." The new sentence, then, will be

High-speed rotating parts must be lubricated sufficiently.

I then ask the students, "For whom did you write this sentence?" None of them can answer. I then explain that this is a regular report sentence. In general, when writing for contract specifications, "must" should be replaced by "shall." For proposals, "must" should be replaced by "should," "might," or "will." For an instruction, an imperative sentence should be written:

Lubricate sufficiently high-speed rotating parts.

Textbooks might begin with the sentence:

You should lubricate...

For a regular report sentence, students can also write:

High-speed rotating parts require (or need) sufficient lubrication.

Here is my last example. Students have written:

When temperature rises, electron movement will be accelerated.

This sentence can be expressed in a "cause and effect" sentence, so I explain that idea and alter the sentence like this: 
High temperature causes electron movement to accelerate.

However, in this sentence, "accelerate" is used as a transitive verb, so "cause" should be replaced by "accelerate" to save words. Thus:

High temperature accelerates electron movement.

Native speakers of English use some useful devices to make difficult ideas sharper and clearer to the readers. Contrast, one of the main devices used in EST, makes several ideas clearer. The following selection contrasts ideas and lists characteristics of each idea:

When the volume of the liquid or gas increases, the temperature is said to rise, whereas a decrease in volume indicates a fall in temperature-CBA, Chemical Systems [4].

The author explains temperature change in liquid and gas by contrasting volume increase to volume decrease. We can take notes about the liquid or gas like this:

1. an increase in volume ... the temperature rises

2. a decrease in volume... the temperature falls

There are many ways to develop sentences, such as coordinate sequence, a subordinate sequence, chronological order, etc. I insist that students place the most important word (and the words that refer to it) at the top as the subject. This is a good example:

"Technology is the application of scientific method and knowledge to industry to satisfy our material needs and wants. This results in new processes and in new products, such as washing machines, record players, motorcars, antibiotics, electronic computers, supermarkets, gramophone records, nuclear weapons, space rockets, and processed food. A technologist has the scientific know-how, or techniques, for making and doing things. The know-how may be original, in that it is devised for a specific purpose, or it may be inherited as the accumulated skill and knowledge of generations of specialists.

It is from this latter tradition that the word technology is derived. It comes 
from the Greek techne, meaning art or skill. In this sense technology has always been with us. It arose thousands of years ago when man first began to master his natural environment by shaping it with fints and with fire.

Technology must be distinguished from science, with which it is often confused because-in the past one hundred years, in particular-there has developed a special and intimate inter-relationship between the two. Until the nineteenth century, the word technology meant the systematic treatment of any thing or subject from dancing to bee-keeping. But during this past century it has come to be endowed with a scientific meaning.--M. Goldsmith, Careers in Technology [5].

In this quotation, all subjects begin with the word "technology" or its equivalent because the paragraphs explain what technology is.

To sum up, rhetoric is an important and necessary topic for EST. Rhetorical competence is an important but undeveloped subject for the Japanese EST practitioners; English grammar tends to be confusing; and technical terms need to be understood, not merely defined in a dictionary.

\section{REFERENCES}

[1] D. S. Halacy. Jr., Nine Roads to Tomorrow, Macrae Smith Company, Philadelphia, PA, p. 45, 1964.

[2] E. Ostroff. Photography, T. Frankel (ed.), Smithsonian Institution Press, Washington, DC, p. 5, 1977.

[3] Y. Shinoda, "Pitfalls for Japanese Specialists in Technical Writing," Journal of Technical Writing and Communication, J. R. Gould (ed.), Vol. 10, No. 2, pp. 103-108, 1980 and IEEE Transactions on Professional Communication, Vol. PC-24, no. 3, pp. 151-152, Sept. 1981.

[4] Chemical Bond Approach Project, Chemical Systems, McGraw-Hill Book Company, Webster Division, New York, p. 295, 1964.

[5] M. Goldsmith, Careers in Technology, Penguin Books, Ltd., Marmondsworth, Middlesex, p. 13, 1963. 